\title{
Correction to: Antibacterial and antioxidant activity of sour cherry kernel oil (Cerasus vulgaris Miller) against some food-borne microorganisms
}

\author{
Maryam Kazempour-Samak ${ }^{1} \cdot$ Ladan Rashidi $^{2}$ (D) Mehrdad Ghavami $^{1} \cdot$ Anoosheh Sharifan $^{1} \cdot$ Fakhrisadat Hosseini $^{3}$
}

Accepted: 18 October 2021 / Published online: 22 October 2021

(c) Springer Science+Business Media, LLC, part of Springer Nature 2021

\section{Correction to: \\ Journal of Food Measurement and Characterization \\ (2021) 15:4686-4695 \\ https://doi.org/10.1007/s11694-021-01035-0}

In this article the affiliation details of co-author Dr. Fakhrisadat Hossein were incorrectly given as 'Department of Biology Science, Faculty of Biotechnology, Alzahra University, Tehran, Iran' but should have been 'Department of Biotechnology, Faculty of Biological Sciences, Alzahra University'.

Publisher's Note Springer Nature remains neutral with regard to jurisdictional claims in published maps and institutional affiliations.

The original article can be found online at https://doi.org/10.1007/ s11694-021-01035-0.

Ladan Rashidi

1.rashidi@standard.ac.ir

1 Department of Food Science and Technology, Faculty of Agriculture, Science and Research Branch, Islamic Azad University, Tehran, Iran

2 Food Technology and Agricultural Products Research Center, Standard Research Institute, PO Box 31745-139, Karaj, Iran

3 Department of Biotechnology, Faculty of Biological Sciences, Alzahra University, Tehran, Iran 